\title{
Characterization of Glutamate Uptake into Synaptic Vesicles
}

\author{
*Shigetaka Naito and ${ }^{*} †$ Tetsufumi Ueda \\ * Mental Health Research Institute and tDepartments of Pharmacology and Psychiatry, The University of Michigan, \\ Ann Arbor, Michigan, U.S.A.
}

\begin{abstract}
Recent evidence indicates that L-glutamate is taken up into synaptic vesicles in an ATP-dependent manner, supporting the notion that synaptic vesicles may be involved in glutamate synaptic transmission. In this study, we further characterized the ATP-dependent vesicular uptake of glutamate. Evidence is provided that a Mg-ATPase, not Ca-ATPase, is responsible for the ATP hydrolysis coupled to the glutamate uptake. The ATP. dependent glutamate uptake was inhibited by agents known to dissipate the electrochemical proton gradient across the membrane of chromaffin granules. Hence, it is suggested that the vesicular uptake of glutamate is driven by electrochemical proton gradients generated by the Mg-ATPase. Of particular interest is the finding that
\end{abstract}

the ATP-dependent glutamate uptake is markedly stimulated by chloride over a physiologically relevant, millimolar concentration range, suggesting an important role of intranerve terminal chloride in the accumulation of glutamate in synaptic vesicles. The vesicular glutamate translocator is highly specific for L-glutamate, and failed to interact with aspartate, its related agents, and most of the glutamate analogs tested. It is proposed that this vesicular translocator plays a crucial role in determining the fate of glutamate as a neurotransmitter. Key Words: Glutamate-Synaptic vesicle-Uptake-Mg-ATPase-Excitatory neurotransmitter. Naito $S$. and Ueda T. Characterization of glutamate uptake into synaptic vesicles. $J$. Neurochem. 44, 99-109 (1985).
Increasing evidence suggests that glutamate functions as a major excitatory neurotransmitter in the CNS (Cotman et al., 1981; Puil, 1981; Watkins and Evans, 1981; Fonnum, 1984). The acidic amino acid excites most neurons in the CNS (Curtis and Johnston, 1974; Krnjević, 1974) through activation of multiple but distinct receptors (McLennan, 1981; Watkins and Evans, 1981; Roberts and Sharif, 1981; Krogsgaard-Larsen and Honoré, 1983; Monaghan et al., 1983) and, as with other neurotransmitters, is released from nerve terminals in a calcium-dependent manner on their depolarization (De Belleroche and Bradford, 1972; Cotman et al., 1981). However, whether glutamate in the nerve terminal is released into the synaptic cleft directly from synaptic vesicles by an exocytotic or other mechanism is not known. Currently available evidence indicates no significant enrichment of glutamate in the isolated synaptic vesicles compared with the other subcellular fractions (Mangan and Whittaker, 1966; Rassin, 1972; Kontro et al., 1980). De Belleroche and Bradford (1973) reported that glutamate was not taken up into the isolated synaptic vesicles, and, based on this and other evidence, they proposed that glutamate is released directly from the cytoplasm of nerve terminals (De Belleroche and Bradford, 1977).

We recently isolated small, spherical synaptic vesicles from the cerebral cortex (Naito and Ueda, 1983), using highly purified antibodies (Naito and Ueda, 1981; Ueda and Naito, 1982) to Protein I, a neuron-specific, synaptic phosphoprotein (Ueda and Greengard, 1977; Greengard, 1981) [recently referred to as Synapsin I (Kennedy et al., 1983)] that is highly concentrated on the surface of synaptic vesicles (Bloom et al., 1979; Ueda et al., 1979; De Camilli et al., 1983), and we demonstrated that Lglutamate is specifically taken up into these vesicles in an ATP- and temperature-dependent but sodiumindependent manner (Naito and Ueda, 1983). These observations have suggested that some of the glutamate within the nerve terminal may be packaged into and accumulated in specific synaptic vesicles, an obligatory process implicit in the exocytotic
Received January 20, 1984; accepted June 6, 1984.

Address correspondence and reprint requests to Dr. Tetsufumi

Ueda, Mental Health Research Institute, The University of Michigan, 205 Washtenaw Place, Ann Arbor, MI 48109, U.S.A.

The present address of Dr. Naito is the Laboratory of Biophysics, NIH-NINCDS, Marine Biology Laboratories, Woods Hole, MA 02543, USA.
Abbreviations used: DCCD, $N, N^{\prime}$-Dicyclohexylcarbodiimide; DTT, Dithiothreitol; FCCP, Carbonyl cyanide $p$ trifluoromethoxyphenylhydrazone; HEPES, $N$-2-Hydroxyethylpiperazine- $N^{\prime}$-2-ethanesulfonic acid; NEM, $N$-Ethylmaleimide. 
mechanism. This notion is also supported by the recent immunocytochemical evidence that glutamate is significantly concentrated in synaptic vesicles (Storm-Mathisen et al., 1983). In view of the potential importance of the vesicular uptake of glutamate in glutamate neurotransmission, we further characterized, in the present study, the ATP-dependent vesicular uptake of glutamate. Evidence provided here suggests that the vesicular glutamate uptake is driven by electrochemical proton gradients generated by a vesicle-associated Mg-ATPase and is markedly potentiated by low concentrations of chloride ions. We also present further evidence for the substrate specificity of the vesicular glutamate translocator.

\section{MATERIALS AND METHODS}

\section{Materials}

L-Glutamic acid, ATP, $N, N^{\prime}$-dicyclohexylcarbodiimide (DCCD), trimethyl tin, potassium thiocyanate, and $N$ ethylmaleimide (NEM) were purchased from Sigma. Dithiothreitol (DTT) was from Aldrich. Potassium isethionate, carbonyl cyanide $p$-nitrofluoromethoxyphenylhydrazone (FCCP), and nigericin were generously provided by Dr. Ronald Holz, Department of Pharmacology, the University of Michigan. All the glutamate and aspartate analogs tested in the experiment described in Table 7 were from Sigma, except for 2-amino-4-phosphonobutyric acid and $\gamma$-methylene glutamic acid, which were the generous gifts of Dr. Carl Cotman, Department of Psychobiology, University of California, Irvine, and Dr. Richard Lawton, Department of Chemistry, the University of Michigan, respectively. $\mathrm{L}-\left[2,3-{ }^{3} \mathrm{H}\right]$ Glutamate acid $(20 \mathrm{Ci} / \mathrm{mmol}$ ) was obtained from Amersham.

\section{Preparation of synaptic vesicles}

A purified synaptic vesicle fraction $(0.4 M$ sucrose layer) was prepared from the bovine cerebral cortex essentially by the same procedure described previously (Ueda et al., 1979), and this vesicle preparation was used in most of the experiments to be described here. For some experiments (as shown in Fig. 2), the synaptic vesicles were further purified by immunoprecipitation with anti-Protein I IgG, as described previously (Naito and Ueda, 1983). The purity of the immunoprecipitated vesicle preparation was at least $90 \%$, as judged by morphology, but the vesicle preparation prior to the anti-Protein I IgG treatment contained some nonvesicular contaminants. The $\mathrm{Na}^{+}, \mathrm{K}^{+}$-ATPase, NADPH-cytochrome $c$ reductase, and cytochrome oxidase activities in the 0.4 $M$ sucrose layer fraction were $1.73 \mu \mathrm{mol} / \mathrm{h} / \mathrm{mg}$ at $37^{\circ} \mathrm{C}$, $3.53 \mathrm{nmol} / \mathrm{min} / \mathrm{mg}$ at $22^{\circ} \mathrm{C}$, and $2.38 \mathrm{nmol} / \mathrm{min} / \mathrm{mg}$ at $22^{\circ} \mathrm{C}$, respectively; these values represented 160,156 , and $173 \%$ of the corresponding enzyme specific activities in the immunoprecipitated vesicle preparation, and $7.4,88$, and $0.4 \%$ of those in the lysed synaptosome preparation (Naito and Ueda, 1983). Although there was some $\mathrm{Na}^{+}-$ dependent glutamate uptake activity in the $0.4 \mathrm{M}$ sucrose layer synaptic vesicle fraction, presumably resulting from contamination with plasma membranes, it represented only $20 \%$ of the ATP-dependent uptake activity. The Nadependent uptake system in the plasma membrane could not contribute significantly to the ATP-dependent uptake activity, since this activity was determined in the absence of $\mathrm{Na}^{+}$, as described below. In this study, the ATP dependency was used as a criterion for uptake into synaptic vesicles.

\section{Assay for vesicular glutamate uptake}

The uptake of glutamate into synaptic vesicles was assayed as described previously (Naito and Ueda, 1983) with a slight modification; the standard sucrose-based glutamate uptake medium (final volume, $100 \mu \mathrm{l}$ ) contained 0.25

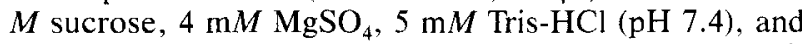
synaptic vesicles ( 20 or $40 \mu \mathrm{g}$ protein). In some experiments, $0.25 M$ sucrose was replaced by $0.11 \mathrm{M} \mathrm{KCl}(\mathrm{KCl}-$ based uptake medium). After incubation of the mixture of synaptic vesicles and buffer in $80 \mu \mathrm{l}$ for $5 \mathrm{~min}$ at $30^{\circ} \mathrm{C}$, $\mathrm{L}-\left[{ }^{3} \mathrm{H}\right]$ glutamate (final concentration, $50 \mu \mathrm{M} ; 0.4 \mathrm{Ci} /$ mmol) and ATP (final concentration, $2 \mathrm{~m} M$; disodium salt; neutralized with Tris base) were added in $20 \mu \mathrm{l}$, and the mixture was further incubated for $1.5 \mathrm{~min}$ at $30^{\circ} \mathrm{C}$. The glutamate uptake was stopped by the addition of 2.5 $\mathrm{ml}$ of ice-cold $0.15 \mathrm{M} \mathrm{KCl}$ and immediate filtration through Millipore HAWP $(25 \mathrm{~mm}, 0.45 \mu \mathrm{m})$ filter. The test tubes were washed with $2.5 \mathrm{ml}$ of $\mathrm{KCl}$ solution three more times, the filters washed an additional three times with the same solution, and radioactivity retained on the filters was determined in ACS (Amersham) by using a liquid scintillation spectrophotometer (Beckman LS 9000). Glutamate uptake was generally measured in duplicate, and the mean and range of duplicate determinations were presented.

The proton-pump ATPase inhibitors (DCCD and trimethyl tin) and electrochemical proton gradient dissipators (FCCP and nigericin) were dissolved in absolute ethanol. In experiments in which the effects of these reagents were examined, the final concentration of ethanol was $0.1 \%$; control assay mixtures contained $0.1 \%$ ethanol.

\section{Assay of ATPase activity and protein determination}

The Mg-ATPase activity of synaptic vesicles was measured as described by Nelson (1980), except that it was assayed in the reaction mixture identical to the glutamate uptake medium, using a higher specific activity of $[\gamma-$ ${ }^{32}$ P]ATP. The amount of protein in the immunoprecipitated synaptic vesicles was estimated as described previously (Naito and Ueda, 1983). Protein of the synaptic vesicle fraction that had not been subjected to immunoprecipitation was determined according to Lowry et al. (1951) with bovine serum albumin as standard.

\section{RESULTS}

\section{Nucleotide specificity for the vesicular uptake of glutamate}

Various nucleotides were tested for their capacity to support the glutamate uptake into synaptic vesicles (Table 1). ATP is the most effective nucleotide in providing energy for the vesicular uptake of glutamate. GTP and ITP are $35-40 \%$ as effective as ATP, whereas UTP is even less effective, and CTP is virtually inactive in supporting the glutamate uptake. Diphosphonucleotides and monophosphonucleotides such as ADP, AMP, and GMP are also 
TABLE 1. Nucleotide specificity for glutamate uptake into synaptic vesicles

\begin{tabular}{ccc}
\hline Nucleotides & $\begin{array}{c}\text { Glutamate uptake } \\
\text { (pmol/1.5 min) }\end{array}$ & $\%$ \\
\hline None & $0.91 \pm 0.09$ & 3.7 \\
ATP & $24.52 \pm 1.02$ & 100 \\
GTP & $9.33 \pm 0.34$ & 38.1 \\
ITP & $8.93 \pm 0.18$ & 36.4 \\
UTP & $4.23 \pm 0.18$ & 17.3 \\
CTP & $1.68 \pm 0.04$ & 6.9 \\
ADP & $1.44 \pm 0.06$ & 5.9 \\
AMP & $0.53 \pm 0.00$ & 2.2 \\
GMP & $1.13 \pm 0.01$ & 4.6 \\
\hline
\end{tabular}

Glutamate uptake was determined in the presence of $2 \mathrm{mM}$ of various nucleotides and $20 \mu \mathrm{g}$ of synaptic vesicles in the standard sucrose-based medium, as described in Materials and Methods.

incapable of driving the glutamate uptake. These results suggest that ATP hydrolysis is required for the vesicular glutamate uptake. In accord with this notion is the observation that the glutamate uptake was inhibited by such agents as DCCD and trimethyl tin, which are known to inhibit Mg-ATPase and thereby to reduce catecholamine and serotonin uptakes into the storage vesicles; $80 \mu M$ DCCD and $25 \mu M$ trimethyl tin inhibited the glutamate uptake into anti-Protein I IgG-precipitated synaptic vesicles by 87 and $99 \%$, respectively. Recent experiments have indicated that there is a qualitative correlation between the trimethyl tin-induced inhibitions of glutamate uptake and Mg-ATPase activity in the synaptic vesicle preparation (data not shown). These results together strongly suggest that a $\mathrm{Mg}$-ATPase, identical or similar to that responsible for the catecholamine and serotonin uptakes, is involved in the ATP-dependent glutamate uptake into the synaptic vesicles.

Effects of varying the concentration of $\mathrm{Mg}^{2+}$ and of various divalent cations

The $\mathrm{Mg}^{2+}$ dependency of the glutamate uptake is shown in Fig. 1. The ATP-dependent glutamate uptake is optimal at $\mathrm{Mg}$ concentrations of $4-8 \mathrm{mM}$. Increasing the $\mathrm{Mg}^{2+}$ concentration beyond $10 \mathrm{mM}$ appears to inhibit the glutamate uptake significantly.

The effects of various divalent metal ions on the ATP-dependent glutamate uptake in the absence or presence of $\mathrm{Mg}^{2+}$ are shown in Table 2. Manganese ions appear to mimic the action of $\mathrm{Mg}^{2+}$ in the ATPdependent glutamate uptake; $\mathrm{Mn}^{2+}$ substitutes for $\mathrm{Mg}^{2+}$ but does not potentiate the uptake activity observed in the presence of $\mathrm{Mg}^{2+}$. It is of interest to note that $\mathrm{Co}^{2+}$ substitutes $\mathrm{Mg}^{2+}$ partially but inhibits the $\mathrm{Mg}^{2+}$-supported glutamate uptake. Calcium ions neither support the glutamate uptake nor cause significant alteration in the $\mathrm{Mg}^{2+}$-supported uptake activity. This indicates that Ca-ATPase is

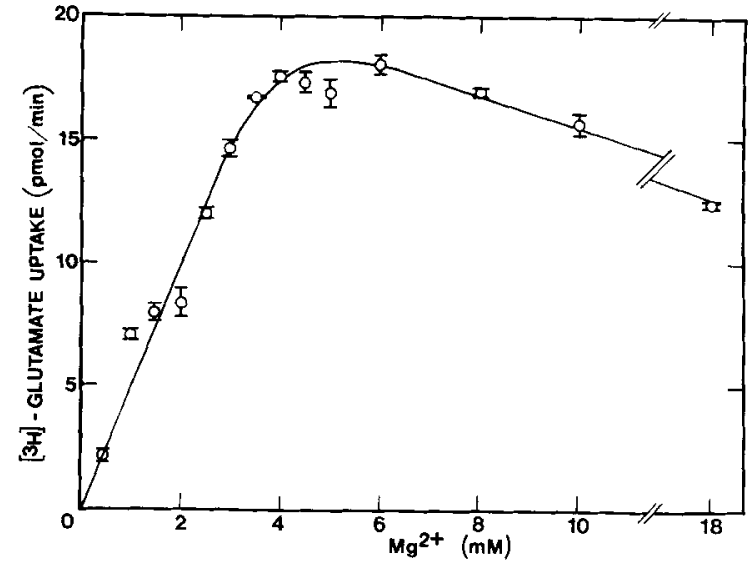

FIG. 1. ATP-dependent uptake rate of glutamate into synaptic vesicles as a function of $\mathrm{Mg}^{2+}$ concentration. Glutamate uptake was determined, using $20 \mu \mathrm{g}$ of synaptic vesicles, in the presence of various concentrations of $\mathrm{Mg}^{2+}$ in the standard sucrose-based medium as described in Materials and Methods.

not involved in the ATP-dependent glutamate uptake into synaptic vesicles. Other divalent metal ions, such as $\mathrm{Fe}^{2+}, \mathrm{Ni}^{2+}, \mathrm{Cu}^{2+}, \mathrm{Cd}^{2+}$, and $\mathrm{Zn}^{2+}$, are all inhibitory in the ATP-dependent glutamate uptake either in the absence or presence of $\mathrm{Mg}^{2+}$, with $\mathrm{Cd}^{2+}$ and $\mathrm{Zn}^{2+}$ being the most potent.

\section{Kinetic constants of the vesicular glutamate} uptake system

The effect of varying the concentration of glutamate on the ATP-dependent glutamate uptake was studied using a virtually homogeneous preparation of the synaptic vesicles, which had been made by immunoprecipitation with anti-Protein I IgG (Fig. 2 ). From the Lineweaver-Burk plot, a single $K_{\mathrm{m}}$ value for glutamate was determined to be $1.6 \mathrm{mM}$ and the $V_{\max }$ value was $13 \mathrm{nmol} / \mathrm{min}-\mathrm{mg}$. ${ }^{1}$ Thus, the ATP-dependent vesicular uptake system for glutamate operates with low affinity for glutamate.

Effect of the permeant anion chloride on vesicular uptake of glutamate

In preliminary experiments, we noticed that when $5 \mathrm{~m} M$ Tris- $\mathrm{Cl}$ ( $\mathrm{pH}$ 7.4) was replaced by $5 \mathrm{~m} M$

\footnotetext{
${ }^{1}$ This number may represent an underestimated $V_{\max }$ value. We have learned that the repeated suspension and high-speed centrifugation of the synaptic vesicles, the step adopted in an effort to remove unbound IgGs (see Naito and Ueda, 1983), results in about $40-50 \%$ denaturation of the ATP-dependent glutamate uptake system, even when the washing procedure is carried out in the absence of IgG. Preliminary evidence has suggested that this denaturation may be in part due to the oxidation of one or more sulfhydryl group(s) of the vesicular glutamate uptake system. This apparent denaturation may largely account for the apparent discrepancy between the $V_{\max }$ value $(13 \mathrm{nmol} /$ $\mathrm{min} / \mathrm{mg}$ ) obtained using the anti-Protein I IgG-precipitated synaptic vesicles and that shown in Table $5(24.9 \mathrm{nmol} / \mathrm{min} / \mathrm{mg})$, which was obtained with vesicles not subjected to the antibody treatment, hence not to the washing procedure.
} 
TABLE 2. Effects of various divalent cations on the ATP-dependent vesicular uptake of glutamate

\begin{tabular}{|c|c|c|}
\hline \multirow[b]{2}{*}{ Cations added } & \multicolumn{2}{|c|}{ Glutamate uptake $(\mathrm{pmol} / 1.5 \mathrm{~min})$} \\
\hline & Without $\mathrm{Mg}^{2+}$ & With $\mathrm{Mg}^{2+}$ \\
\hline None & $4.0 \pm 0.1$ & $24.5 \pm 0.22$ \\
\hline $\mathrm{Mg}^{2+}$ & $26.1 \pm 0.4$ & - \\
\hline $\mathrm{Mn}^{2+}$ & $29.0 \pm 1.3$ & $22.5 \pm 0.2$ \\
\hline $\mathrm{Co}^{2+}$ & $13.2 \pm 0.1$ & $11.1 \pm 0.2$ \\
\hline $\mathrm{Ca}^{2+}$ & $4.6 \pm 0.2$ & $19.3 \pm 0.2$ \\
\hline $\mathrm{Fe}^{2+}$ & $2.8 \pm 0.1$ & $8.9 \pm 1.1$ \\
\hline $\mathrm{Ni}^{2+}$ & $2.7 \pm 0.2$ & $3.2 \pm 0.0$ \\
\hline $\mathrm{Cu}^{2+}$ & $0.6 \pm 0.0$ & $0.7 \pm 0.1$ \\
\hline $\mathrm{Cd}^{2+}$ & $0.3 \pm 0.3$ & 0 \\
\hline $\mathrm{Zn}^{2+}$ & $0.1 \pm 0.0$ & 0 \\
\hline
\end{tabular}

The ATP-dependent glutamate uptake was measured, using 20 $\mu \mathrm{g}$ of synaptic vesicles, in the presence of various divalent metal ions ( $4 \mathrm{mM}$ each) in the absence or presence of $4 \mathrm{mM} \mathrm{MgSO}$ in the standard sucrose-based medium, as described in Materials and Methods. The counter-anions of the tested cations were all sulfate, except for $\mathrm{Mg}^{2+}$ and $\mathrm{Ca}^{2+}$, which were paired with acetate.

Tris-maleate ( $\mathrm{pH} 7.4$ ) or Tris- $N$-2-hydroxyethylpiperazine- $N^{\prime}$-2-ethanesulfonic acid (HEPES) (pH 7.4), the ATP-dependent glutamate uptake activity was reduced to about one-third to one-fifth of that observed in the presence of Tris-Cl. This result suggested that chloride ions can cause a substantial stimulation of the glutamate uptake. In the experiments shown in Fig. 3, we examined the effects of various concentrations of chloride ion on the ATPdependent vesicular uptake of glutamate in Tris-maleate. When the uptake experiment was carried out in the presence of $50 \mu \mathrm{M}$ glutamate, the glutamate concentration used in the standard assay of gluta-

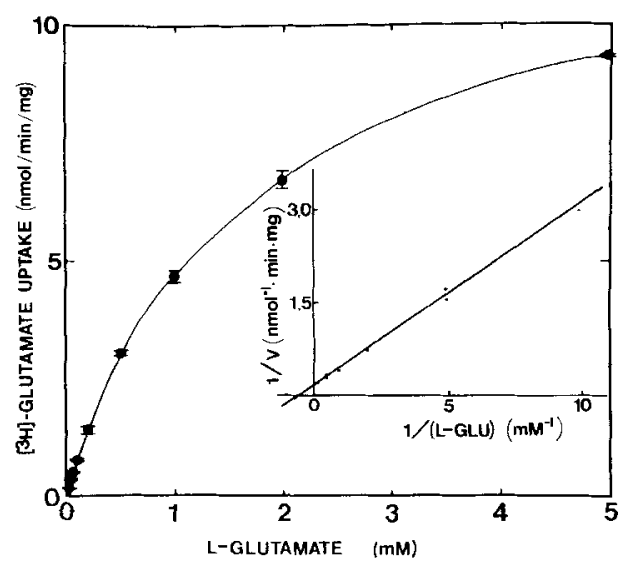

FIG. 2. Rate of ATP-dependent vesicular uptake of glutamate as a function of glutamate concentration. L-Glutamate uptake into anti-Protein I IgG-precipitated synaptic vesicles (20 $\mu \mathrm{g})$ was measured at $1.5 \mathrm{~min}$ at $30^{\circ} \mathrm{C}$ in the presence of various concentrations of $L-\left[{ }^{3} \mathrm{H}\right]$ glutamate $(50 \mu M-5 \mathrm{mM})$ in the standard sucrose-based medium, as described in Materials and Methods. The inset shows a Lineweaver-Burk plot of the kinetic data. mate uptake, low concentrations (1-4 $\mathrm{m} M$ ) of chloride were found to cause a marked potentiation of the glutamate uptake, whereas concentrations higher than $10 \mathrm{~m} M$ attenuated the stimulatory effect (Fig. 3A). In contrast to the permeating chloride, the impermeant monovalent anion isethionate exhibited little effect at all the concentrations tested. When the uptake experiment was carried out in the presence of $1 \mathrm{~m} M$ glutamate, the inhibitory effect of chloride was attenuated (Fig. 3B). This suggests that the inhibition by relatively high concentrations of chloride may in part be caused by a possible interaction between chloride and the glutamate binding site. In accord with this interpretation is the observation that the $K_{\mathrm{m}}$ value for glutamate was increased about fivefold in the presence of $0.11 \mathrm{M}$ $\mathrm{KCl}$ (see Table 5). These results indicate that the ATP-dependent glutamate uptake is highly stimulated by low concentrations of chloride but is subject to inhibition by high concentrations of chloride.

Ion specificity for stimulation of vesicular uptake of glutamate

To determine the ion specificity for the potentiation and inhibition of the vesicular glutamate uptake, various salts were tested for their capacity to alter the glutamate uptake. As shown in Table 3, $\mathrm{KCl}, \mathrm{NaCl}, \mathrm{LiCl}$, and choline chloride all showed similar degrees of stimulation at $4 \mathrm{mM}$ and inhibition at $50 \mathrm{mM}$, suggesting that the monovalent cations may play little or no role in the vesicular glutamate uptake. When the anion of potassium salts was varied, chloride and bromide were found to be the only anions capable at $4 \mathrm{~m} M$ of marked potentiation; iodide and sulfate showed only a slight stimulation, nitrate was without effect, and fluoride, acetate, and phosphate appeared to cause a small inhibition. At $50 \mathrm{mM}$, all the anions but chloride were inhibitory, with nitrate, iodide, and fluoride being the most potent. These results indicate that the ATP-dependent glutamate uptake into synaptic vesicles is selectively stimulated by low concentrations (e.g., $4 \mathrm{mM}$ ) of chloride or bromide.

Effects of chloride on the kinetic parameters of the ATP-dependent vesicular uptake of glutamate

Kinetic experiments were carried out in the absence and presence of $2 \mathrm{mM} \mathrm{KCl}$ to determine the effects of a low concentration of chloride on $V_{\max }$ of the glutamate uptake and $K_{\mathrm{m}}$ for glutamate. The $V_{\max }$ values in the absence and presence of $2 \mathrm{~m} M$ $\mathrm{KCl}$ in $5 \mathrm{~m} M$ Tris-maleate buffer ( $\mathrm{pH}$ 7.4) were determined to be $6.1 \pm 0.8$ and $22.6 \pm 1.9 \mathrm{nmol} / \mathrm{min} /$ $\mathrm{mg}(\mathrm{n}=3)$, respectively; the corresponding $K_{\mathrm{m}}$ values were $0.84 \pm 0.16$ and $1.12 \pm 0.01 \mathrm{~m} M(\mathrm{n}=$ 3 ), respectively. That is, the stimulatory effect of chloride is caused by an increase in $V_{\max }$ of the uptake system and not by changes in $K_{\mathrm{m}}$ for glutamate.

The effects of varying the concentration of ATP on the vesicular uptake of glutamate in the absence 

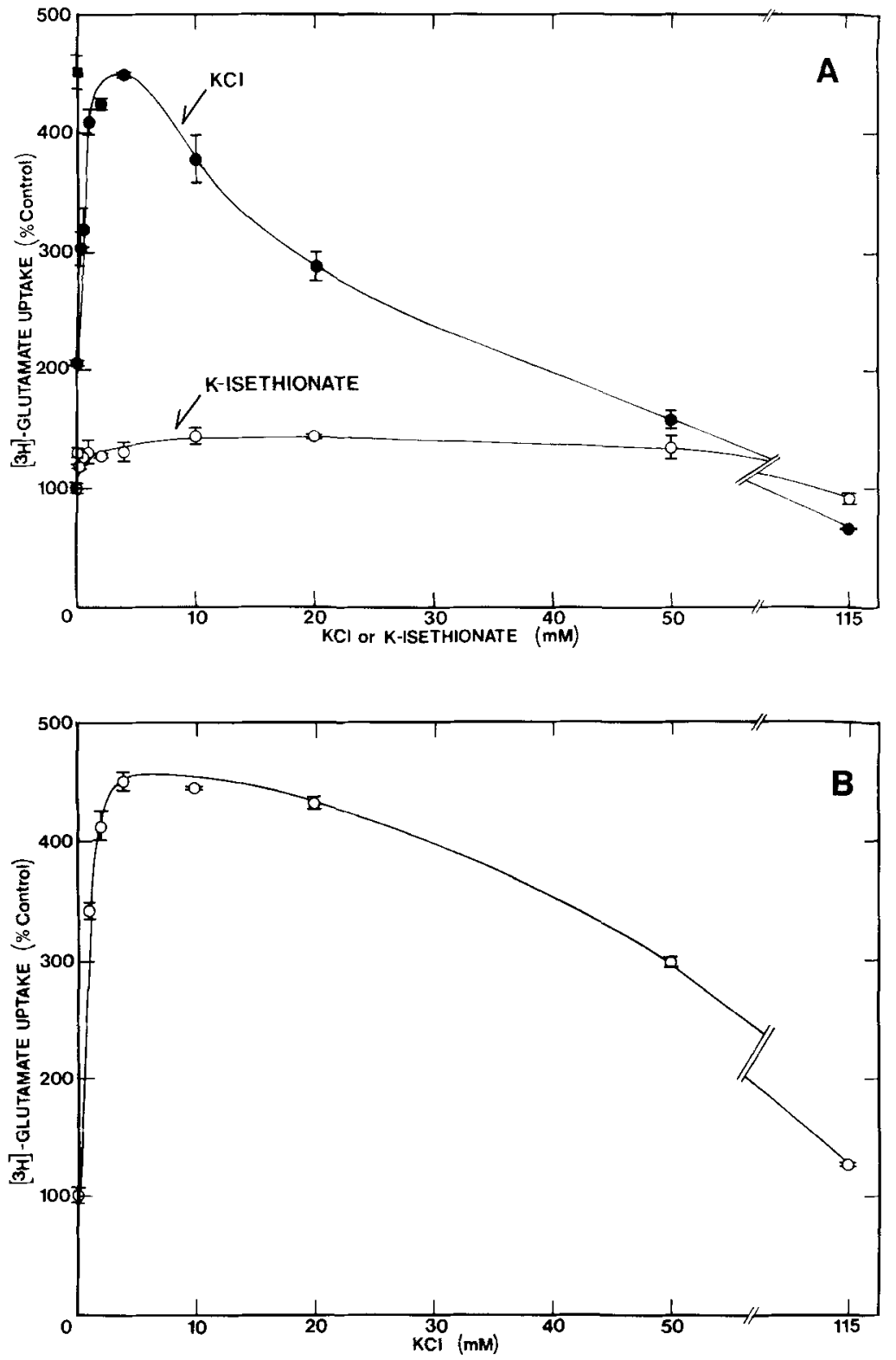

FIG. 3. Effects of varying the concentrations of chloride and isethionate on the ATP-dependent vesicular uptake of glutamate. A: Glutamate uptake was determined, using $20 \mu \mathrm{g}$ synaptic vesicles, in the presence of various concentrations of $\mathrm{KCl}(0)$ or $\mathrm{K}$-isethionate $(0)$ in the $0.25 \mathrm{M}$ sucrose- $5 \mathrm{mM}$ Tris-maleate ( $\mathrm{pH} 7.4$ ) medium, as otherwise described in Materials and Methods. The glutamate uptake activity in the absence of these agents was $4.24=0.14$ pmol $(n=2)$, and was expressed as $100 \%$. For comparison, the uptake activity in the standard sucrose-based medium which contained $5 \mathrm{mM}$ Tris-HCl buffer $(\mathrm{pH} 7.4)$ instead of Trismaleate buffer was also measured ( $\boldsymbol{C})$. B: The uptake was determined in the presence of 1 $\mathrm{m} M$, rather than $50 \mu M, L-\left[{ }^{3} \mathrm{H}\right]$ glutamate $(20$ $\mu \mathrm{Ci} / \mathrm{mmol})$, and of various concentrations of $\mathrm{KCl}$. Otherwise, the assay conditions were the same as described in (A). The glutamate uptake in the absence of $\mathrm{KCl}$ was $42.4 \pm 2.1$ $\mathrm{pmol} / 1.5 \mathrm{~min}$, and was expressed as $100 \%$. and presence of $4 \mathrm{mM} \mathrm{KCl}$ are shown in Fig. 4. In the absence of $\mathrm{KCl}$, the $K_{\mathrm{m}}$ for ATP was determined to be $1.2 \mathrm{mM}$, and the $V_{\max }$ value was $340 \mathrm{pmol} /$ $\mathrm{min} / \mathrm{mg}$ with $50 \mu M$ glutamate, according to the linear regression analysis of the double-reciprocal plot of the data. In the presence of $4 \mathrm{mM} \mathrm{KCl}$, the glutamate uptake exhibited a peculiar response to increasing concentrations of ATP. The concentration of ATP that gave rise to a maximal uptake activity was approximately $2 \mathrm{~m} M$; increasing the concentration further brought about a transient inhibition. The concentration required for half-maximal activity was estimated to be about $0.2 \mathrm{mM}$. The maximal activity at $2 \mathrm{mM}$ ATP (and $50 \mu M$ glutamate) was $900 \mathrm{pmol} / \mathrm{min} / \mathrm{mg}$. It appears that a low concentration of $\mathrm{KCl}$ increases not only the maximal glutamate uptake activity but also the affinity for ATP. It is noted that the low concentration of $\mathrm{KCl}$ stimulates the glutamate uptake to larger degrees at submillimolar concentrations of ATP than at higher concentrations.

pH dependency of the vesicular glutamate uptake

The effects of the $\mathrm{pH}$ of the extravesicular medium on the ATP-dependent uptake of glutamate into synaptic vesicles in the absence and presence of $4 \mathrm{mM} \mathrm{KCl}$ are shown in Fig. 5. In the absence of $\mathrm{KCl}$, a maximal uptake occurred at $\mathrm{pH} 6.3$, whereas that in the presence of $\mathrm{KCl}$ was observed over the $\mathrm{pH}$ range $6.8-7.4$. It is of interest that the 
TABLE 3. Effects of various ions on the vesicular uptake of glutamate

\begin{tabular}{lccr}
\hline & \multicolumn{3}{c}{ Glutamate uptake (pmol/1.5 min) } \\
\cline { 2 - 4 } Salts added & $0 \mathrm{mM}$ & $4 \mathrm{mM}$ & \multicolumn{1}{c}{$50 \mathrm{~m} M$} \\
\hline $\mathrm{KCl}$ & $7.0 \pm 0.2$ & $24.9 \pm 0.0$ & $8.1 \pm 0.1$ \\
$\mathrm{NaCl}$ & - & $24.3 \pm 0.0$ & $10.1 \pm 0.0$ \\
$\mathrm{LiCl}$ & - & $23.7 \pm 0.2$ & $9.9 \pm 0.1$ \\
$\mathrm{Choline}-\mathrm{Cl}$ & - & $22.9 \pm 0.2$ & $8.4 \pm 0.5$ \\
$\mathrm{KBr}$ & - & $21.6 \pm 0.2$ & $4.1 \pm 0.0$ \\
$\mathrm{~K}_{2} \mathrm{SO}_{4}$ & - & $11.0 \pm 0.0$ & $5.3 \pm 0.2$ \\
$\mathrm{KI}$ & - & $10.7 \pm 0.2$ & $1.2 \pm 0.1$ \\
$\mathrm{KNO}$ & - & $7.5 \pm 0.3$ & $1.1 \pm 0.0$ \\
$\mathrm{KF}$ & - & $5.0 \pm 0.1$ & $1.8 \pm 0.1$ \\
Potassium & & & \\
acetate & - & $5.8 \pm 0.2$ & $3.3 \pm 0.1$ \\
$\quad$ (pH 7.4) & - & & \\
Potassium & & & \\
$\quad$ phosphate & & & \\
$\quad$ pH 7.4) & - & $5.0 \pm 0.1$ & $2.7 \pm 0.1$ \\
\hline
\end{tabular}

The ATP-dependent uptake of glutamate was measured, using $20 \mu \mathrm{g}$ of synaptic vesicles, in the absence or presence of various ions ( $4 \mathrm{~m} M$ and $50 \mathrm{mM}$ ) in the $0.25 M$ sucrose $/ 5 \mathrm{~m} M$ Tris-maleate ( $\mathrm{pH}$ 7.4) medium, as otherwise described in Materials and Methods.

stimulatory effect of chloride is highly dependent on the $\mathrm{pH}$ of the external medium; the largest $\mathrm{KCl}-$ stimulated glutamate uptake occurs between $\mathrm{pH} 6.8$ and $\mathrm{pH} 7.4$.

\section{Possible mechanism for ATP-dependent vesicular} uptake of glutamate

To gain a clue as to the mechanism by which ATP hydrolysis is coupled to the glutamate uptake into synaptic vesicles, the effects of the proton ionophore $\mathrm{FCCP}$, thiocyanate, the $\mathrm{H}^{+} / \mathrm{K}^{+}$ionophore nigericin, and ammonia on the ATP-dependent vesicular uptake of glutamate were examined. As shown

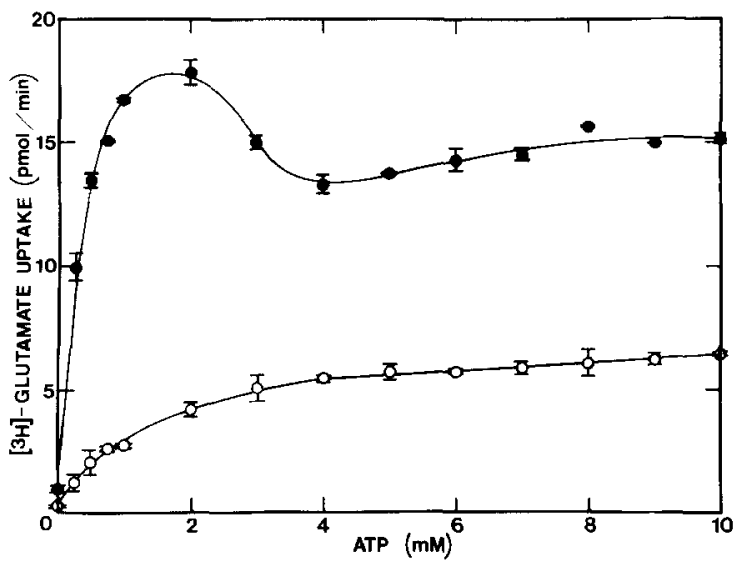

FIG. 4. Vesicular uptake of glutamate as a function of ATP concentration. L-glutamate uptake was determined, using 20 $\mu \mathrm{g}$ synaptic vesicles, in the presence of various concentrations of ATP, in the absence $(O)$ or presence $(0)$ of $4 \mathrm{mM}$ $\mathrm{KCl}$ in the $0.25 \mathrm{M}$ sucrose $/ 4 \mathrm{mM}$ Tris-maleate medium, as otherwise described in Materials and Methods.

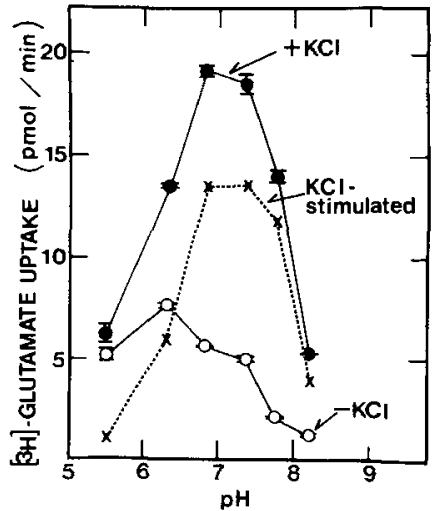

FIG. 5. Effect of extravesicular $\mathrm{pH}$ on the ATP-dependent glutamate uptake into synaptic vesicles. The glutamate uptake into synaptic vesicles $(20 \mu \mathrm{g})$ was assayed at various $\mathrm{pHs}$ in the absence $(O)$ or presence $(0)$ of $4 \mathrm{mM} \mathrm{KCl}$ in 20 $\mathrm{mM}$ Tris-HEPES/0.25 $M$ sucrose, as otherwise described in Materials and Methods. The difference between the uptake in the presence and that in the absence of $\mathrm{KCl}$ was also plotted $(x---x)$.

in Table 4, FCCP, nigericin in the presence of $\mathrm{K}^{+}$, and $\mathrm{NH}_{4}^{+}$(which is in equilibrium with $\mathrm{NH}_{3}$ and $\mathrm{H}^{+}$) all caused significant inhibition of the ATPdependent glutamate uptake, either in the absence or presence of $4 \mathrm{mM}$ chloride. Table 5 shows that the membrane potential dissipator potassium thiocyanate also inhibits the ATP-dependent vesicular uptake of glutamate, and that both FCCP and thiocyanate cause the inhibition largely by affecting $V_{\max }$ of the vesicular glutamate uptake system and only to a small extent the affinity for glutamate. The $\mathrm{pH}$ gradient dissipating agents ammonium chloride and nigericin reduced the $V_{\max }$ value but did not significantly alter the affinity for glutamate, when the uptake was carried out in the presence of a high concentration of $\mathrm{KCl}$, a condition under which presumably the $\mathrm{pH}$ gradient predominates as a result of a large influx of chloride, allowing further proton translocation. These results together suggest that the vesicular uptake of glutamate may be driven by electrochemical proton gradients generated by a vesicular Mg-ATPase. However, the quantitative correlation between the glutamate uptake and the membrane potential and the $\mathrm{pH}$ gradient remains to be established.

\section{Effects of sulfhydryl agents on vesicular uptake of glutamate}

In view of the possibility that the inhibitory effect of some of the metal ions may be due to the blockade of a sulfhydryl group(s) of the ATP-dependent uptake system, we investigated the effects of NEM as well as $\mathrm{Cd}^{2+}$ and $\mathrm{Zn}^{2+}$ on the glutamate uptake in the absence and presence of DTT. As shown in Table 6, NEM caused a potent inhibition and this inhibition was blocked by DTT. Similarly, the $\mathrm{Cd}^{2+}$ and $\mathrm{Zn}^{2+}$-induced inhibitions were also 
TABLE 4. Effects of electrochemical proton gradient dissipating agents on the vesicular uptake of glutamate

\begin{tabular}{lrrrrr}
\hline & \multicolumn{5}{c}{ Glutamate uptake (pmol/1.5 min) } \\
\cline { 2 - 6 } \multicolumn{1}{c}{ Additions } & $\mathrm{No} \mathrm{KCl}$ & $\%$ & $4 \mathrm{mM} \mathrm{KCl}$ & $\%$ & KCl-stimulated \\
\hline None & $49.9 \pm 1.0$ & 100 & $151.2 \pm 10.3$ & 100 & 101.3 \\
Nigericin $(7 \mu M)$ & $51.4 \pm 1.5$ & 103 & $152.8 \pm 8.5$ & 101 & 101.4 \\
$\mathrm{~K}_{2} \mathrm{SO}_{4}(20 \mathrm{mM})$ & $36.9 \pm 0.5$ & 74 & $88.7 \pm 0.0$ & 59 & 51.8 \\
$\mathrm{Nigericin}(7 \mu M)^{\text {plus } \mathrm{K}_{2} \mathrm{SO}}(20 \mathrm{~m} M)$ & $22.7 \pm 4.2$ & 46 & $35.2 \pm 0.1$ & 23 & 12.5 \\
$\left(\mathrm{NH}_{4}\right)_{2} \mathrm{SO}_{4}(20 \mathrm{mM})$ & $22.8 \pm 0.3$ & 46 & $71.2 \pm 1.7$ & 47 & 48.4 \\
$\mathrm{FCCP}_{2}(2 M)$ & $9.1 \pm 0.8$ & 18 & $39.6 \pm 0.5$ & 26 & 30.5 \\
\hline
\end{tabular}

The ATP-dependent glutamate uptake was determined in the absence or presence of 4 $\mathrm{m} M \mathrm{KCl}$ in $5 \mathrm{~m} M$ Tris-maleate buffer instead of Tris-HCl buffer. In this experiment, synaptic vesicles $(40 \mu \mathrm{g})$ were first preincubated in the presence of test agent in the $0.25 \mathrm{M}$ sucrose/ $5 \mathrm{~m} M$ Tris-maleate ( $\mathrm{pH} \mathrm{7.4)}$ medium for $5 \mathrm{~min}$ at $30^{\circ} \mathrm{C}$. Uptake was then initiated by the addition of $\mathrm{L}-\left[^{3} \mathrm{H}\right] \mathrm{glutamate}$ (final concentration, $1 \mathrm{mM} ; 20 \mathrm{mCi} / \mathrm{mmol}$ ) and allowed to contimue for $1.5 \mathrm{~min}$.

prevented by DTT. These results suggest that one or more reduced cysteine residue(s) is important in the ATP-dependent vesicular uptake of glutamate, and that $\mathrm{Cd}^{2+}$ and $\mathrm{Zn}^{2+}$ achieve their inhibition by reacting with the sulfhydryl group of critical cysteine residues.

\section{Structural requirement for vesicular uptake by the glutamate translocator}

To characterize the substrate recognition site of the glutamate translocator, various glutamate analogs were tested for their capacity to compete for vesicular uptake of L-glutamate (Table 7). Among

TABLE 5. Effects of membrane potential-and pH gradient-dissipating reagents on the kinetic parameters of the vesicular uptake of glutamate

\begin{tabular}{lcc}
\hline \multicolumn{1}{c}{ Additions } & $K_{\mathrm{m}}(\mathrm{m} M)$ & $\begin{array}{c}V_{\max } \\
(\mathrm{nmol} / \mathrm{min} / \mathrm{mg})\end{array}$ \\
\hline In sucrose medium & & \\
$\quad$ None (control) & $1.26 \pm 0.04$ & $24.9 \pm 2.6$ \\
$\mathrm{KSCN}(2.5 \mathrm{mM})$ & $2.45 \pm 0.25 \dagger$ & $16.1 \pm 0.8^{*}$ \\
FCCP $(2 \mu M)$ & $2.29 \pm 0.26^{* *}$ & $15.7 \pm 2.2^{*}$ \\
In KCl medium & & \\
None (control) & $6.00 \pm 1.55$ & $13.9 \pm 0.8$ \\
$\mathrm{NH}_{4} \mathrm{Cl}(20 \mathrm{mM})$ & $5.66 \pm 1.10$ & $6.5 \pm 0.9^{\dagger}$ \\
Nigericin $(3.5 \mu M)$ & $4.76 \pm 0.21$ & $5.6 \pm 0.3 \ddagger$ \\
\hline
\end{tabular}

The ATP-dependent glutamate uptake was determined both in the standard sucrose-based medium and in the $0.11 \mathrm{M} \mathrm{KCl}$ medium as described in Materials and Methods. The preincubation of synaptic vesicles $(40 \mu \mathrm{g})$ was carried out in the absence or presence of inhibitors, followed by the addition of several concentrations of $\mathrm{L}-\left[{ }^{3} \mathrm{H}\right]$ glutamate (final concentrations: $0.5,0.65$, $0.91,1.5$, and $5 \mathrm{~m} M$ ) together with ATP. Uptake was allowed to occur for $1.5 \mathrm{~min}$. The $K_{\mathrm{m}}$ and $V_{\max }$ values were calculated by linear regression analysis of Lineweaver-Burk plot of the data thus obtained. These results represent the means \pm SEM of three experiments, each conducted in duplicate using three vesicle preparations.

$* \mathrm{p}<0.05 ; * * \mathrm{p}<0.01 ; \uparrow \mathrm{p}<0.005 ; \mathrm{p}<0.0005$ (compared with control) by two-tailed $t$ test. the agents tested, DL- $\gamma$-methylene glutamate and DL- $\alpha$-methyl glutamate showed the most significant inhibition; although these glutamate analogs were less potent than L-glutamate itself, they were more potent than D-glutamate in inhibiting the uptake of L-glutamate. This finding suggests that $\mathrm{L}-\gamma$-methylene glutamate and L- $\alpha$-methyl glutamate would be even more potent than their racemic mixtures. In contrast, those analogs in which a functional group of glutamate is modified or altered had no significant effect on the vesicular uptake of L-glutamate. These agents include L-glutamine, glutarate, $\alpha$-ketoglutarate, $N$-methyl L-glutamate, $\gamma$-methyl or ethyl L-glutamate, L-glutamic acid dimethyl ester, and L-glutamic acid diethyl ester, 2-amino-4-phosphonobutyrate, and L-homocysteate. Moreover, those analogs that have a shorter or longer carbon chain length than glutamate showed little or no interaction with the glutamate translocator. These analogs include aspartate, its agonist $N$-methyl D-aspartate, its antagonist $\alpha$-aminoadipate, and $\alpha$-ami-

TABLE 6. Effects of sulfhydryl agents on the vesicular uptake of glutamate

\begin{tabular}{lrc}
\hline & \multicolumn{2}{c}{ Glutamate uptake $(\mathrm{pmol} / 1.5 \mathrm{~min})$} \\
\cline { 2 - 3 } \multicolumn{1}{c}{ Additions } & \multicolumn{1}{c}{ No DTT } & $2 \mathrm{~m} M$ DTT \\
\hline None & $21.1 \pm 0.6$ & $22.6 \pm 0.1$ \\
NEM $(0.05 \mathrm{~m} M)$ & $2.1 \pm 0.7$ & $21.0 \pm 0.2$ \\
NEM $(0.1 \mathrm{~m} M)$ & $1.2 \pm 0.1$ & $21.9 \pm 1.7$ \\
$\mathrm{CdSO}_{4}(0.1 \mathrm{~m} M)$ & $1.1 \pm 0.0$ & $21.0 \pm 0.5$ \\
$\mathrm{ZnSO}_{4}(0.1 \mathrm{~m} M)$ & $9.2 \pm 0.6$ & $19.6 \pm 0.4$ \\
\hline
\end{tabular}

The ATP-dependent glutamate uptake was determined using $20 \mu \mathrm{g}$ synaptic vesicles, in the standard sucrose-based medium as described in Materials and Methods, except that the preincubation of synaptic vesicles was carried out in the absence or presence of NEM $(0.05 \mathrm{~m} M$ and $0.1 \mathrm{~m} M)$, cadmium sulfate $(0.1$ $\mathrm{m} M)$, or zinc sulfate $(0.1 \mathrm{~m} M)$, each case in the absence or presence of $2 \mathrm{~m} M$ DTT. 
TABLE 7. Effects of glutamate analogs on the vesicular uptake of glutamate

\begin{tabular}{|c|c|c|}
\hline \multirow[b]{2}{*}{ Test agents } & \multicolumn{2}{|c|}{ L- $\left[{ }^{3} \mathbf{H}\right]$ Glutamate uptake } \\
\hline & cpm & $\%$ \\
\hline None (control) & $7932 \pm 193$ & 100 \\
\hline L-Glutamate & $2152+28$ & $27 \pm 0$ \\
\hline DL- $\gamma$-Methylene glutamate & $3116 \pm 268$ & $39 \pm 3$ \\
\hline 1)L- $\alpha$-Methyl glutamate & $4064 \pm 188$ & $51 \pm 2$ \\
\hline D-Glutamate & $5392 \pm 56$ & $68 \pm 1$ \\
\hline L-Glutamine & $9308 \pm 88$ & $117 \pm 1$ \\
\hline Glutarate & $7668 \pm 318$ & $97 \pm 4$ \\
\hline$\alpha$-Ketoglutarate & $7992 \pm 424$ & $101 \pm 5$ \\
\hline$N$-Methyl-L-glutamate & $6968 \pm 100$ & $88 \pm 1$ \\
\hline$\gamma$-Methyl-L-glutamate & $8508+144$ & $107 \pm 2$ \\
\hline$\gamma$-Ethyl-L-glutanate & $9104 \pm 220$ & $115 \pm 3$ \\
\hline L-Glutamic acid dimethylester & $6548 \pm 80$ & $83 \pm 1$ \\
\hline L.-Glutamic acid diethylester & $7464 \pm 740$ & $94 \pm 9$ \\
\hline L-Aspartate & $8228+196$ & $104 \pm 2$ \\
\hline D-Aspartate & $8832 \pm 84$ & $111=1$ \\
\hline$N$-Methyl-D-aspartate & $8108 \pm 60$ & $102 \pm 1$ \\
\hline Kainate & $7672 \pm 40$ & $97 \pm 1$ \\
\hline 2-Amino-4-phosphonobutyrate & $7560 \pm 276$ & $95 \pm 3$ \\
\hline L-Homocysteate & $6844 \pm 88$ & $86 \pm 1$ \\
\hline$D-\alpha$-Aminoadipate & $6424 \pm 208$ & $81 \pm 3$ \\
\hline$L-\alpha$-Aminoadipate & $6352 \pm 216$ & $80 \pm 3$ \\
\hline DL- $\alpha$-Aminopimelate & $8432 \pm 780$ & $106 \pm 10$ \\
\hline Quisqualate & $7872 \pm 167$ & $99 \pm 2$ \\
\hline Ibotenate & $8100 \pm 100$ & $102 \pm 1$ \\
\hline
\end{tabular}

The ATP-dependent glutamate uptake was determined, using $20 \mu \mathrm{g}$ of synaptic vesicles in the standard sucrose-based medium containing $50 \mu M$ L. $-\left[^{3} \mathrm{H}\right]$ glutamate as described in Materials and Methods, except that various test agents (each $5 \mathrm{mM}$ ) were included in the preincubation medium. Glutamate analogs were neutralized with $\mathrm{KOH}$ when necessary. Uptake in the control (no addition) was $7,932 \pm 193 \mathrm{cpm}$ after the subtraction of an averaged blank value $(82 \mathrm{cpm})$.

nopimelate. Finally, the glutamate-related potent neurotoxic excitants kainate and ibotenate, and the glutamate agonist quisqualate all failed to exhibit any significant interaction with the vesicular glutamate translocator. These results all indicate that the glutamate translocator specifically recognizes all the unmodified functional groups, the skeletal carbon chain length, and the L-configuration of glutamate.

\section{DISCUSSION}

In this study, we provided evidence that suggests that the ATP-dependent uptake of glutamate into synaptic vesicles is driven by an electrochemical proton gradient generated by Mg-ATPase, a mechanism analogous to that for catecholamine and serotonin uptakes into storage granules (Holz, 1978; Njus and Radda, 1978; Johnson et al., 1979; Carty et al., 1981). The driving force is derived specifically from ATP (Table 1). This and the previous observation (Naito and Ueda, 1983) that the unhydrolyzable ATP analog $\beta, \gamma$-methylene ATP failed to support the glutamate uptake indicate that the cleavage of $\gamma$-phosphate of ATP is required for the glutamate uptake. It is likely that the ATP hydrolysis coupled to the glutamate uptake is catalyzed by a $\mathrm{Mg}$-ATPase, since $\mathrm{Mg}^{2+}$, not $\mathrm{Ca}^{2+}$, is required in addition to ATP for the glutamate uptake (Table 2 ); since the glutamate uptake is strongly inhibited by DCCD and trimethyl tin, agents known to inhibit the $\mathrm{Mg}$-ATPase in the membrane of chromaffin granules and thereby inhibit catecholamine uptake into the storage granules (Johnson et al., 1979; Carty et al., 1981); and since the trimethyl tininduced inhibition of glutamate is correlated with the inhibition of Mg-ATPase by trimethyl tin in the synaptic vesicle preparation (S. Naito and T. Ueda, unpublished observation). As in the case of the MgATPase coupled to the catecholamine and acetylcholine uptakes (Hasselbach and Taugner, 1970; Holz, 1978; Parsons and Koenigsberger, 1980), it appears that one or more cysteine sulfhydryl group(s) is essential for the vesicular proton pump Mg-ATPase activity coupled to glutamate uptake, since NEM inhibited not only the glutamate uptake (Table 6) but also the vesicular Mg-ATPase activity (S. Naito and T. Ueda, unpublished observation).

According to our scheme, the Mg-ATPase, on hydrolysis of ATP, translocates protons from the outside to the inside of the synaptic vesicle and thereby generates a membrane potential, positive inside, analogous to the Mg-ATPase in the chromaffin granule membrane (Bashford et al., 1975). The vesicle membrane potential thus produced could provide a driving force for the transport of glutamate into the synaptic vesicles, since those agents known to reduce the membrane potential and inhibit the catecholamine uptake into chromaffin granules, such as FCCP and thiocyanate (Holz, 1978; Johnson and Scarpa, 1979; Johnson et al., 1979), caused a substantial reduction in the glutamate uptake (Tables 4 and 5). When permeant anions are present at sufficient concentrations in the medium outside the vesicle, the membrane potential would cause an influx of anion, which would decrease the membrane potential and result in the formation of $\mathrm{pH}$ gradients across the membrane. Evidence given here suggests that the $\mathrm{pH}$ gradient can also provide a driving force for the glutamate uptake; the ATPdependent glutamate uptake observed in the presence of $0.11 \mathrm{M}$ potassium chloride was inhibited by nigericin, an $\mathrm{H}^{+} / \mathrm{K}^{+}$ionophore, or ammonia (Table 5 ), both of which are known to reduce $\mathrm{pH}$ gradients across the chromaffin granule membrane and inhibit the catecholamine uptake (Johnson et al., 1978; Johnson and Scarpa, 1979).

An intriguing feature of this study is the observation that the ATP-dependent glutamate uptake is altered by chloride; low concentrations (2-4 $\mathrm{mM}$ ) of chloride stimulate the ATP-dependent glutamate uptake markedly, whereas excess chloride attenuates the stimulatory effect (Fig. 3). The chloride stimulation is highly dependent on the presence of 
ATP in the medium (Fig. 4). The stimulatory effect of anions on the glutamate uptake is quite specific to chloride and bromide (Table 3). The stimulatory effect of chloride could have physiological significance, since the maximally effective concentration of chloride $(4 \mathrm{mM})$ lies well within the cytosolic concentration range (Woodbury, 1965). If the local concentration of chloride within the nerve ending should change in the low millimolar range in response to a depolarization of the nerve ending, chloride ions could play a regulatory role in vivo in the accumulation of glutamate in synaptic vesicles. Even if it should not change, our observation still suggests the importance of chloride in the accumulation of glutamate in endogenous synaptic vesicles, and possibly in glutamate synaptic transmission.

The chloride stimulatory effect is represented by an increase in $V_{\max }$ of the glutamate uptake system. The mechanism by which the maximal velocity is increased is not well understood at present. It is possible that this change in $V_{\max }$ is brought about by an increase in $\mathrm{pH}$ gradient across the vesicle membrane, which could occur as a result of an influx of the permeant anion chloride. This interpretation is consistent with the observation that the ATP-dependent glutamate uptake activity in the presence of $4 \mathrm{~m} M$ chloride was inhibited by nigericin in the presence of $\mathrm{K}^{+}$to a larger degree than in the absence of $\mathrm{K}^{+}$and that the chloride-stimulated uptake activity was substantially reduced by nigericin (Table 4). Thus, it is feasible that the maximal uptake of glutamate occurs in the presence of both an optimal membrane potential and an optimal $\mathrm{pH}$ gradient, as in the case of the catecholamine uptake into chromaffin granules (Johnson et al., 1979). The evaluation of this possibility, however, requires direct measurements of the $\mathrm{pH}$ gradient and membrane potential across the synaptic vesicle membrane, and the demonstration of a quantitative correlation between the electrochemical proton gradient and the ATP-dependent glutamate uptake.

Since it has been reported that chloride (at relatively high concentrations) stimulates the $\mathrm{Mg}$ ATPase activity in chromaffin granule membranes (Pazoles et al., 1980), we tested the possibility that the chloride stimulation of glutamate uptake might be due to an increase in the Mg-ATPase activity. However, we did not observe any significant effect of $4 \mathrm{~m} M$ chloride on the Mg-ATPase activity in the synaptic vesicle preparation, which was assayed under conditions identical to those under which glutamate uptake was measured (data not shown). We could not rule out the possibility entirely, though, that the Mg-ATPase coupled to the glutamate uptake may represent a small population of the total $\mathrm{Mg}$-ATPase present in the synaptic vesicle preparation and that a small concentration (such as 4 $\mathrm{m} M$ ) of chloride may stimulate this specific popu- lation of Mg-ATPase molecules. An alternative possibility, not testable at present, is that chloride may increase the maximal velocity of the glutamate uptake by changing the conformation of the glutamate translocator, or protein presumably distinct from the Mg-ATPase.

It is conceivable that the inhibition of glutamate uptake by high concentrations of chloride is in part due to a reduction of the membrane potential to suboptimal levels, which could be brought about by the influx of chloride, as observed in the chromaffin granule membrane (Johnson et al., 1979). The inhibitory effect of high concentrations of chloride could also in part be attributable to competition for a glutamate binding site on the glutamate translocator. This view is supported by the observations that, at higher concentrations of glutamate, higher concentrations of chloride are required to exhibit the inhibition (Fig. 3B), and that $K_{\mathrm{m}}$ for glutamate is increased significantly by high concentrations of chloride (Table 5).

In contrast to our evidence for the vesicular uptake of glutamate, De Belleroche and Bradford reported that exogenously added glutamate was not bound to or taken up into the isolated synaptic vesicles (De Belleroche and Bradford, 1973). It is likely that this apparent failure in their attempt to demonstrate the in vitro uptake of glutamate into the synaptic vesicles resulted from the omission of ATP (or ATP plus chloride) from their incubation medium. Our previous (Naito and Ueda, 1983) and present studies clearly indicate that ATP is essential for the vesicular uptake of glutamate and that the ATP-dependent uptake is further enhanced by low concentrations of chloride.

However, glutamate has never been found to be at a particularly high concentration in the isolated synaptic vesicles, as compared to its level in the other subcellular fractions (Mangan and Whittaker, 1966; Rassin, 1972; Kontro et al., 1980). The lack of evidence for the enrichment of glutamate in the isolated vesicles has been attributed to the possible leakage of the amino acid during the vesicle preparation. In agreement with this notion, we have observed that the tritiated glutamate, which had been taken up in the presence of ATP and chloride into the isolated synaptic vesicles, leaked out substantially when the vesicles were subjected to hypotonic conditions for $30 \mathrm{~min}$ (data not shown). Hence, the previous lack of evidence for the vesicular uptake or accumulation of glutamate would not necessarily rule out the possibility that synaptic vesicles are involved in glutamate synaptic transmission.

The competition experiments with various glutamate analogs presented here (Table 7) suggest that the primary amino group at the $\alpha$-carbon of glutamate is an essential component for recognition by the vesicular glutamate translocator. Hence, the modifications of the amino group to secondary 
amino groups, as seen in $N$-methyl-L-glutamate and kainate, resulted in a loss of or substantial decrease in the capacity to compete with L-glutamate for binding to the translocator. Replacement of the $\alpha$ amino group with a keto group as in $\alpha$-ketoglutarate or its removal as in glutarate also led to the loss of the interaction with the glutamate binding site. In addition to the primary amino group and $\alpha$-carboxyl group, the $\gamma$-carboxyl group of glutamate is also an important element for recognition by the glutamate translocator. Thus, glutamine, $\gamma$-methyl or ethyl ester of glutamic acid, $\alpha$-aminophosphonobutyrate in which the $\gamma$-carboxyl group is replaced by a phosphono group, and L-homocysteate in which the $\gamma$ carboxyl group is replaced by a sulfono group are all devoid of or deficient in the capacity to interact with the glutamate translocator. It is of interest to note that the glutamate receptor antagonists L-glutamic acid diethyl ester and $\alpha$-aminophosphonobutyrate (Koerner and Cotman, 1981; Fagg et al., 1982) and the excitatory amino acid L-homocysteate (McLennan, 1981; Watkins and Evans, 1981) are not recognized by the glutamate translocator. Moreover, the potent glutamate analog excitants quisqualate and ibotenate (McLennan and Lodge, 1979; Watkins and Evans, 1981), both of which lack the $\gamma$-carboxyl group, failed to inhibit the glutamate uptake. Finally, the vesicular glutamate translocator has a high degree of specificity with respect to the carbon chain. Thus, the translocator recognized only the five-carbon straight-chain $\alpha$-amino dicarboxylates; it showed the lack of interaction with the four-, six-, and seven-carbon $\alpha$-amino dicarboxylates, namely, aspartate, $\alpha$-aminoadipate, and $\alpha$ aminopimelate, respectively.

The above evidence indicates that the electrochemical proton gradient-sensitive glutamate translocator in the synaptic vesicle has a unique structural specificity. The vesicular glutamate translocator is distinct from the sodium-dependent glutamate transporters in the plasma membrane, neuronal or nonneuronal, which do not distinguish between glutamate and aspartate (Logan and Snyder, 1972; Schousboe and Hertz, 1981; Christensen and Makowske, 1983), and from the glutamate receptors coupled to neuronal excitation, which are known to interact with diethyl glutamate and quisqualate. The distinct nature of the vesicular glutamate translocator is also indicated by the kinetic experiments (Fig. 2), which have shown that the vesicular translocator has low affinity for glutamate $\left(K_{\mathrm{m}}=1.6 \mathrm{mM}\right)$, in contrast to the plasma membrane sodium-dependent glutamate transporters (Logan and Snyder, 1972; Schousboe and Hertz, 1981; Christensen and Makowske, 1983) and sodium-independent glutamate binding proteins, which have higher affinities for glutamate (Roberts and Sharif, 1981; Michaelis et al., 1983). Perhaps the substantially higher concentration of glutamate in the cell than in the extracellular milieu makes it unnecessary for the intracellular organelle synaptic vesicle to possess a high-affinity uptake system for glutamate.

The remarkably narrow substrate/inhibitor specificity of the translocator would enable a selective vesicular accumulation of glutamate among various amino acids present in nerve endings. In fact, it was observed that only negligible amounts of aspartate, $\gamma$-aminobutyric acid, and glycine were taken up into those highly purified synaptic vesicles (anti-Protein I IgG-precipitated vesicles) that have high glutamate uptake activity (Naito and Ueda, 1983). Based on these unique properties, we suggest that the electrochemical proton gradient-sensitive glutamate translocator plays an important role in the in vivo accumulation of glutamate in certain synaptic vesicles, and thus determines the fate of the amino acid as a neurotransmitter. However, evidence for a direct release of vesicular glutamate into the synaptic cleft remains to be sought.

Acknowledgments: This work was supported in part by a Biomedical Research Support Grant from the University of Michigan, Medical School. We are thankful to Dr. Gardner C. Quarton for his encouragement and support; Dr. Ronald Holz for his discusssions on some of the experiments using electrochemical gradient dissipators; Professor Halvor Christensen and Dr. Junichi Shioi for their comments on the manuscript; James M. Larson and Lawrence M. Sichel for their technical assistance in the preparation of synaptic vesicles; and Mary Roth for her excellent assistance in the preparation of the manuscript.

\section{REFERENCES}

Bashford C. L., Radda G. K., and Ritchie G. A. (1975) Energylinked activities of the chromaffin granule membrane. FEBS Lett. 50, 21-24.

Bloom F. E., Ueda T., Battenberg E., and Greengard P. (1979) Immunocytochemical localization, in synapses, of Protein $I$, an endogenous substrate for protein kinases in mammalian brain. Proc. Natl. Acad. Sci. USA 76, 5982-5986.

Carty S. E., Johnson R. G., and Scarpa A. (1981) Serotonin transport in isolated platelet granules. J. Biol. Chem. 256, $11244-11250$.

Christensen H. N. and Makowske M. (1983) Recognition chemistry of anionic amino acids for hepatocyte transport and for neurotransmittory action compared. Life Sci. 33, 22552267.

Cotman C. W., Foster A. C., and Lanthorn T. H. (1981) An overview of glutamate as a neurotransmitter, in Glutamate as a Neurotransmitter (Di Chiara G. and Gessa G. L., eds), pp. 1-27. Raven Press, New York.

Curtis D. R. and Johnston G. A. R. (1974) Amino acid transmitters in the mammalian CNS. Ergeb. Physiol. 69, 97-188.

De Belleroche J. S. and Bradford H. F. (1972) Metabolism of beds of mammalian cortical synaptosomes: response to depolarizing influences. J. Neurochem. 19, 585-602.

De Belleroche J. S. and Bradford H. F. (1973) Amino acids in synaptic vesicles from mammalian cerebral cortex: a reappraisal. J. Neurochem. 21, 441-451.

De Belleroche J. S. and Bradford H. F. (1977) On the site of origin of transmitter amino acids released by depolarization of nerve terminals in vitro. $J$. Neurochem. $29,335-343$. 
De Camilli P., Harris S. M. Jr., Huttner W. B., and Greengard P. (1983) Synapsin (Protein I), a nerve terminal-specific phosphoprotein. II. Its specific association with synaptic vesicles demonstrated by immunocytochemistry in agarose-embedded synaptosomes. J. Cell Biol. 96, 1355-1373.

Fagg G. E., Foster A. C., Mena E. E., and Cotman C. W. (1982) Chloride and calcium ions reveal a pharmacologically distinct population of $\mathrm{L}$-glutamate binding sites in synaptic membranes: correspondence between biochemical and electrophysiological data. J. Neurosci. 2, 958-965.

Fonnum F. (1984) Glutamate: a neurotransmitter in mammalian brain. J. Neurochem. 42, 1-11.

Greengard P. (1981) Intracellular signals in the brain. Harvey Lect. 75, 277-331.

Hasselbach W. and Taugner G. (1970) The effect of a crossbridging thiol reagent on the catecholamine fluxes of adrenal medulla vesicles. Biochem. J. 119, 265-271.

Holz R. W. (1978) Evidence that catecholamine transport into chromaffin vesicles is coupled to vesicle membrane potential. Proc. Natl. Acad. Sci. USA 75, 5190-5194.

Johnson R. G. and Scarpa A. (1979) Protonmotive force and catecholamine transport in isolated chromaffin granules. $J$. Biol. Chem. 254, 3750-3760.

Johnson R. G., Carlson N. J., and Scarpa A. (1978) $\Delta \mathrm{pH}$ and catecholamine distribution in isolated chromaffin granules. J. Biol. Chem. 253, 1512-1521.

Johnson R. G., Pfister D., Carty S. E., and Scarpa A. (1979) Biological amine transport in chromaffin ghosts. J. Biol. Chem. 254, 10963-10972.

Kennedy M. B., McGuinness T., and Greengard P. (1983) A calcium/calmodulin-dependent protein kinase from mammalian brain that phosphorylates Synapsin I: partial purification and characterization. $J$. Neurosci. 3, 818-831.

Koerner J. F. and Cotman C. W. (1981) Micromolar L-2-aminophosphonobutyric acid selectively inhibits perforant path synapses from lateral entorhinal cortex. Brain Res. 216, $192-198$.

Kontro P., Marnela K.-M., and Oja S. S. (1980) Free amino acids in the synaptosome and synaptic vesicle fractions of different bovine brain areas. Brain Res. 184, 129-141.

Krnjević K. (1974) Chemical nature of synaptic transmission in vertebrates. Physiol. Rev. 54, 418-540.

Krogsgaard-Larsen P. and Honoré T. (1983) Glutamate receptors and new glutamate agonists. TIPS 4, 31-33.

Logan W. J. and Snyder S. H. (1972) High affinity uptake systems for glycine, glutamic and aspartic acids in synaptosomes of rat central nervous tissues. Brain Res. 42, 413431.

Lowry O. H., Rosebrough N. J., Farr A. L., and Randall R. J. (1951) Protein measurement with the Folin phenol reagent. J. Biol. Chem. 193, 265-275.

Mangan J. L. and Whittaker V. P. (1966) The distribution of free amino acids in subcellular fractions of guinea-pig brain. Biochem. J. 98, 128-137.

McLennan H. (1981) On the nature of the receptors for various amino acids in the mammalian central nervous system, in Glutamate as a Neurotransmitter (Di Chiara G. and Gessa G. L., eds), pp. 253-262. Raven Press, New York.

McLennan $H$. and Lodge D. (1979) The antagonism of amino acid-induced excitation of spinal neurons in the cat. Brain Res. 169, 83-90.

Michaelis E. K., Michaelis M. L., Stormann T. M., Chittenden
W. L., and Grubbs R. D. (1983) Purification and molecular characterization of the brain synaptic membrane glutamatebinding protein. $J$. Neurochem. 40, 1742-1753.

Monaghan D. T., Holets V. R., Toy D. W., and Cotman C. W. (1983) Anatomical distributions of four pharmacologically distinct ${ }^{3} \mathrm{H}-\mathrm{L}$-glutamate binding sites. Nature 306, 176- 179 .

Naito S. and Ueda T. (1981) Affinity-purified anti-Protein I antibody. J. Biol. Chem. 256, 10657-10663.

Naito S. and Ueda T. (1983) Adenosine triphosphate-dependent uptake of glutamate into Protein I-associated synaptic vesicles. J. Biol. Chem. 258, 696-699.

Nelson N. (1980) Coupling factors from higher plants. Methods Enzymol. 69, 301-313.

Njus D. and Radda G. K. (1978) Biogenic processes in chromaffin granules. A new perspective on some old problems. Biochim. Biophys. Acta 463, 219-244.

Parsons S. M. and Koenigsberger R. (1980) Specific stimulated uptake of acetylcholine by Torpedo electric organ synaptic vesicles. Proc. Natl. Acad. Sci. USA 77, 6234-6238.

Pazoles C. J., Creutz C. E., Ramu A., and Pollard H. B. (1980) Permeant anion activation of MgATPase activity in chromaffin granules. J. Biol. Chem. 255, 7863-7869.

Puil E. (1981) S-Glutamate: its interactions with spinal neurons. Brain Res. Rev. 3, 229-322.

Rassin D. K. (1972) Amino acids as putative transmitters: failure to bind to synaptic vesicles of guinea pig cerebral cortex. $J$. Neurochem. 19, 139-148.

Roberts P. J. and Sharif N. A. (1981) Radioreceptor binding studies with glutamate and aspartate, in Glutamate as a Neurotransmitter (Di Chiara G. and Gessa G. L., eds), pp. 295-305. Raven Press, New York.

Schousboe A. and Hertz L. (1981) Role of astroglial cells in glutamate homeostasis, in Glutamate as a Neurotransmitter (Di Chiara G. and Gessa G. L., eds), pp. 103-113. Raven Press, New York.

Storm-Mathisen J., Leknes A. K., Bore A. T., Vaaland J. L.., Edminson P., Haug F.-M. S., and Ottersen O. P. (1983) First visualization of glutamate and GABA in neurones by immunocytochemistry. Nature $301,517-520$.

Toll L., Gundersen C. B. Jr., and Howard B. D. (1977) Energy utilization in the uptake of catecholamines by synaptic vesicles and adrenal chromaffin granules. Brain Res. 136, 5966.

Ueda T. and Greengard P. (1977) Adenosine 3':5'-monophosphate-regulated phosphoprotein system of neuronal membranes. I. Solubilization, purification, and some properties of an endogenous phosphoprotein. J. Biol. Chem. 252, $5155-5163$.

Ueda T. and Naito S. (1982) Specific inhibition of the phosphorylation of Protein I, a synaptic protein, by affinity-purified anti-Protein I antibody. Prog. Brain Res. 56, 87-103.

Ueda T., Greengard P., Berzins K., Cohen R. S., Blomberg F., Grab D. J., and Siekevitz P. (1979) Subcellular distribution in cerebral cortex of two proteins phosphorylated by a cAMP-dependent protein kinase. J. Cell Biol. 83, 308-319.

Watkins J. C. and Evans R. H. (1981) Excitatory amino acid transmitters. Annu. Rev. Pharmacol. Toxicol. 21, 165-204.

Woodbury J. W. (1965) The cell membrane: ionic and potential gradients and active transport, in Physiology and Biophysics (Ruch T. C. and Patton H. D., eds), pp. 1-25. W. B. Saunders, Philadelphia. 